\title{
The Incidence of Work-related Low Back Pain among Currently Practicing Physiotherapists in Bloemfontein
}

\begin{abstract}
Physiotherapy practice involves the performance of strenuous physical activities related to the delivery of patient rehabilitation. No evidence of studies relating to physiotherapy work-related low back pain (WRLBP) in South Africa could be found. The aims of this study were to retrospectively investigate the incidence of work related low back pain among currently practicing physiotherapists in Bloemfontein, to determine the contributing risk factors, and to determine the responses of the physiotherapists to injury. Eighty four physiotherapists participated in this descriptive study. The results indicated that $67 \%$ of respondents had experienced work related low back pain and the $95 \%$ confidence interval for the incidence of WRLBP among physiotherapists in Bloemfontein is [56.8\%; 76.6\%]. Therapists performing cardio-thoracic related

\author{
Birch J, B.Sc (Physio) ${ }^{2}$ \\ Cloete MM, B.Sc (Physio) ${ }^{2}$ \\ Joubert L, B.Sc (Physio) ${ }^{2}$
}

Barnes R, MSc (Physio) ${ }^{1}$

Usher AC, B.Sc (Physio) ${ }^{2}$

Nel M, M. Med.Sc ${ }^{3}$

\footnotetext{
${ }^{1}$ Lecturer/Study leader, Department of Physiotherapy, Faculty of Health Sciences, University of the Free State.

2 4th year Physiotherapy Students, Department of Physiotherapy, Faculty of Health Sciences, University of the Free State.

3 Biostatician, Department of Biostatistics, University of the Free State.
} tasks had the most significant confidence interval of WRLBP [2.2\%; 35.1\%]. Fifty eight percent of respondents who had WRLBP reported that their symptoms were exacerbated by clinical practice. The results of the study suggest that it is the nature of the job design which predisposes physiotherapists to injury and not a lack of kinetic handling knowledge. Further research is needed to develop methods to reduce the risks of WRLBP which are inherently part of physiotherapy practice.
\end{abstract}

KEY WORDS: INCIDENCE, WORK RELATED LOWER BACK PAIN, SOUTH AFRICA.

\section{INTRODUCTION}

"We tend to think that we're not going to get hurt because we have all this knowledge about on the job injuries. Our knowledge of ergonomics might help us avoid injury, but we're still forced into bad postures, and we're lifting more than we should." Glover (2002)

International research studies suggest that musculoskeletal injuries among healthcare workers are common and physiotherapists are no exception, despite their specialist knowledge of body mechanics and injury prevention. The term "work-related musculoskeletal disorders" describes a wide range of inflammatory and degenerative diseases and disorders that result in pain and functional impairment. They arise when individuals are exposed to work activities and conditions that significantly contribute to their development or exacerbation of symptoms, but which may not be the sole cause of the musculoskeletal disorders (World Health Organisation,
1985). The practice of physical therapy requires the performance of many labour-intensive tasks related to the delivery of patient care. Such activities include lifting, bending, twisting, reaching, performing manual therapy, and maintaining awkward positions for a prolonged period of time. Therefore, physiotherapists in certain working environments are exposed to occupational risk factors which may predispose them to work-related low back pain (Holder et al, 1999).

Ninety one percent of physiotherapists in Australia experienced work related musculoskeletal disorders (WRMSD) at some time during their career and one in six physiotherapists moved within, or left the profession as a result of this (Cromie et.al. 2000). Research done among physiotherapists in Zimbabwe, Australia and the USA revealed that $56 \%-63 \%$ suffered from work related low back pain (WRLBP) (Cromie et.al. 2001; Holder et.al. 1999, Igumbor et.al.
2003). No evidence of studies relating to physiotherapy work related low back pain in South Africa could be found and as a starting point in determining this incidence, the aims of this research study were to retrospectively investigate the incidence of work related low back pain among currently practicing physiotherapists in Bloemfontein, to determine the contributing risk factors and to determine the response of the physiotherapists to injury.

\section{CORRESPONDENCE TO:}

Mrs Roline Barnes

Department of Physiotherapy

Faculty of Health Sciences

University of the Free State

P.O. Box 339 (G30),

Bloemfontein 9300

South Africa

Tel: $\quad+27-51-4013295$

Fax: +27-51-4013304

Email: GNFTRB.MD@mail.uovs.ac.za 


\section{METHODOLOGY}

A descriptive study was used. Previous studies were used to compile the questionnaire. The study population included all qualified and currently practicing physiotherapists in Bloemfontein.

\section{Data Collection}

Afrikaans and English copies of the questionnaire were hand delivered to 115 participants. A high response rate of $72,17 \%$ was achieved. A pilot study was conducted to enhance the face and content validity of the questionnaire and the results were not included in the final outcome of the study.

\section{Statistical analysis}

Statistical analysis was done by the Department of Biostatistics at the University of the Free State using the 95\% confidence interval, percentiles, means and percentages. The statistical significance accepted as $\mathrm{p}<0.05$.

\section{RESULTS}

The total number of participants were eighty three $(n=83)$, seventy five respondents were female and eight were male. The age range of respondents was between 23 - 64 years with the median age of respondents being 32 years. The median number of years that respondents had been practicing physiotherapy was 8.5 years.

The results showed that $67.5 \%$ of respondents had experienced work related low back pain and that the $95 \%$ confidence interval for the incidence of WRLBP among physiotherapists in Bloemfontein is [56.8\%; 76.6\%]. These values compare to studies done in Zimbabwe (Igumbor et al. 2003), North and Central Queensland, Australia (Gardner, D. and West, D. 2001) and in the U.S.A (Holder et al. 1999) where the incidence was $56 \%, 22 \%$ and $62 \%$ respectively. Twenty two $(26.5 \%)$ respondents reported a work related lower back injury. Twenty seven $(32.6 \%)$ of the respondents had a lower back injury/pain caused by factors outside of physiotherapy. Table 1 shows the comparison of respondents with and without back pain in relation to place of work.

Physiotherapists working in the cardio thoracic area had the most statistically significant $95 \%$ confidence interval $[2,2 \% ; 35,1 \%]$ when comparing respondents with and without work related low back pain. Therapists working in private practice, manipulative therapy and orthopaedic settings showed a high occurence of work related low back pain.

The type of tasks showing a statistically significant confidence interval for work related low back pain were mobilisations/manipulations. Tasks showing a tendency towards the development of work related low back pain included chest physiotherapy and rehabilitation. Coincidentally a high percentage of

Table 1: Comparison of respondents with and without back pain in relation to place of work.

\begin{tabular}{|c|c|c|c|}
\hline & $\begin{array}{l}\text { RESPONDENTS } \\
\text { WITH BACK PAIN }\end{array}$ & $\begin{array}{l}\text { RESPONDENTS } \\
\text { WITHOUT BACK PAIN }\end{array}$ & $\begin{array}{l}\text { 95\% CONFIDENCE } \\
\text { INTERVAL FOR \% DIFFERENCE }\end{array}$ \\
\hline Place of work & Percentage & Percentage & \\
\hline General Hospital & $19.2 \%$ & $80.8 \%$ & {$[-26.6 \% ; 7.1 \%]$} \\
\hline Cardio thoracic* & $28.6 \%$ & $7.4 \%$ & {$[2.2 \% ; 35.1 \%]$} \\
\hline Paediatrics & $37.5 \%$ & $22.2 \%$ & {$[-6.5 \% ; 32.8 \%]$} \\
\hline Academia & $16.1 \%$ & $29.6 \%$ & [-38.8\% ; 4.5\%] \\
\hline Administration & $7.1 \%$ & $18.5 \%$ & {$[-30.1 \% ; 2.9 \%]$} \\
\hline Rehabilitation\# & $41.1 \%$ & $25.9 \%$ & {$[-7.1 \% ; 33.4 \%]$} \\
\hline Nursing Home & $10.7 \%$ & $0 \%$ & {$[-3.0 \% ; 21.5 \%]$} \\
\hline School system & $10.7 \%$ & $18.5 \%$ & {$[-26.9 \% ; 7.1 \%]$} \\
\hline Orthopaedics\# & $41.1 \%$ & $25.9 \%$ & {$[-7.1 \% ; 33.4 \%]$} \\
\hline Manipulative therapy\# & $50 \%$ & $29.6 \%$ & {$[-2.3 \% ; 39.1 \%]$} \\
\hline Neurology & $30.4 \%$ & $14.8 \%$ & {$[-5 \% ; 31.3 \%]$} \\
\hline Sport & $39.3 \%$ & $25.9 \%$ & {$[-8.7 \% ; 31.6 \%]$} \\
\hline Community Health & $12.5 \%$ & $3.7 \%$ & {$[-7.1 \% ; 20.3 \%]$} \\
\hline Private practice\# & $62.5 \%$ & $37.5 \%$ & {$[-14.4 \% ; 28.5 \%]$} \\
\hline Spinal & $16.1 \%$ & $18.5 \%$ & {$[-22.1 \% ; 13.2 \%]$} \\
\hline Home care & $10.7 \%$ & $3.7 \%$ & {$[-8.6 \% ; 18.2 \%]$} \\
\hline Gerontology & $8.9 \%$ & $3.8 \%$ & {$[-10.2 \% ; 16.0 \%]$} \\
\hline Other & $8.9 \%$ & $7.4 \%$ & {$[-15.2 \% ; 13.2 \%]$} \\
\hline
\end{tabular}

\footnotetext{
* Significant \# Tendency
} 
physiotherapists who perform mobilisations/manipulations, chest physiotherapy and rehabilitation were also indicated that they have low back pain.

\section{Refer to Table 2:}

Mobilisations/manipulations as well as chest physiotherapy force therapists to work in cramped or awkward positions, in the same position for long periods of time and to reach away from their bodies. Spinal rehabilitation usually requires lifting or transferring of dependant patients, as well as bending or twisting one's back in an awkward way. Unanticipated sudden movements or falls of a patient can also occur.

It was surprising from the results that electrotherapy was included in the group of settings showing a tendency towards WRLBP, as it is not generally regarded as a strenuous task. It is however possible that because electrotherapy is often used in combination with mobilisations/manipulations that it is related to WRLBP. Only $1.8 \%$ of therapists suffering from WRLBP indicated that they substitute manual techniques with electrotherapy to reduce strain on their bodies when treating patients.

There seems to be a relationship between the cardio thoracic work setting and the task of chest physiotherapy due to the fact that a large proportion of the work in this area is chest physiotherapy. Work in the hospital setting also includes a fair portion of chest physiotherapy and $42.9 \%$ of the respondents' injuries occurred in a hospital setting.

Interestingly $87.5 \%$ of respondents indicated that they experienced low back pain during the performing of administration tasks. This could be attributed to the position in which the administration tasks are performed or the ergonomics of the working stations/ computers.

The highest occurrence of the initial episode of WRLBP was within the first five years after graduation. This correlates with other studies (Igumbor et al. 2003), (Holder et al. 1999), (Cromie et al. 2001) and (Bork et.al.1996). Further research needs to be performed in order to establish possible reasons. Seventy five percent of respondents with WRLBP indicated that the onset of symptoms were predominantly gradual.

\section{Refer to Table 3:}

In the opinion of respondents, major contributors to work related low back discomfort or injury were: working in awkward or cramped positions, working in a position for long periods of time, bending or twisting one's back in an awkward way, unanticipated sudden movements or falls of a patient and lifting or transferring dependent patients. $56.9 \%$ of respondents indicated that inadequate training in injury prevention was not a contributing factor to the development of work related low back pain in physiotherapists.

\section{Refer to Table 4:}

On the question how participants responded to injury $71.4 \%$ of respondents consulted another physiotherapist and $71.4 \%$ undertook a posture and exercise programme. Fifty percent of respondents indicated that they modified their techniques in order to prevent their low back pain and $50 \%$ of physiotherapists with low back pain took medication to alleviate their symptoms. Only $7.1 \%$ of respondents elected to change the type of patients predominantly treated or took time off on sick leave and $38.2 \%$ stated that their symptoms prevented them from doing normal activities of daily life or leisure activities. A study including retired physiothera-

Table 2: Comparison between the percentiles of respondents with and without low back pain in correlation with task.

\begin{tabular}{|l|l|l|l|}
\hline & $\begin{array}{l}\text { RESPONDENTS } \\
\text { WITH BACK PAIN }\end{array}$ & $\begin{array}{l}\text { RESPONDENTS } \\
\text { WITHOUT BACK PAIN }\end{array}$ & $\begin{array}{l}\text { 95\% CONFIDENCE } \\
\text { INTERVAL FOR \% DIFFERENCE }\end{array}$ \\
\hline Type of task & Percentage & Percentage & \\
\hline Manipulation/Mobilisation* & $83.9 \%$ & $16.1 \%$ & {$[17.8 \% ; 7.9 \%]$} \\
\hline Administration & $87.5 \%$ & $12.5 \%$ & {$[-9.2 \% ; 25.3 \%]$} \\
\hline Cardio thoracic & $16.1 \%$ & $11.1 \%$ & {$[-13.5 \% ; 18.8 \%]$} \\
\hline Neurology & $41.1 \%$ & $25.9 \%$ & {$[-7.1 \% ; 33.4 \%]$} \\
\hline Electrotherapy\# & $62.5 \%$ & $37.5 .7 \%$ & {$[-0.9 \% ; 41.6 \%]$} \\
\hline Rehabilitation\# & $67.9 \%$ & $32.1 \%$ & {$[-2.4 \% ; 40.2 \%]$} \\
\hline $\begin{array}{l}\text { Education/Training of } \\
\text { clients or students }\end{array}$ & $41.1 \%$ & $55.6 \%$ & {$[-35.1 \% ; 7.9 \%]$} \\
\hline Sports physiotherapy\# & $48.2 \%$ & $29.2 \%$ & {$[-29.4 \% ; 11.1 \%]$} \\
\hline Paediatrics & $25.0 \%$ & $33.3 \%$ & {$[-6.2 \% ; 36.4 \%]$} \\
\hline Orthopaedics & $53.6 \%$ & $37.0 \%$ & {$[-0.8 \% ; 28.5 \%]$} \\
\hline Spinal\# & $19.6 \%$ & $3.7 \%$ & {$[-0.6 \% ; 41.8 \%]$} \\
\hline Chest physiotherapy\# & $69.6 \%$ & $30.4 \%$ & \\
\hline
\end{tabular}

* Significant \# Tendency 
Table 3: Identified job-related risk factors and their relative contributions to the development of WRLBP in physiotherapists.

\begin{tabular}{|c|c|c|c|c|}
\hline & Major & Moderatel & Mild & Not at all \\
\hline Performing the same task over and over & $38.5 \%$ & $38.5 \%$ & $15.4 \%$ & $7.6 \%$ \\
\hline Treating a large number of patients in one day & $43.6 \%$ & $38.2 \%$ & $12.7 \%$ & $5.5 \%$ \\
\hline Not enough rest breaks during the day & $26.9 \%$ & $34.6 \%$ & $26.9 \%$ & $11.5 \%$ \\
\hline Performing manual orthopaedic techniques & $4.0 \%$ & $36.0 \%$ & $40.0 \%$ & $20.0 \%$ \\
\hline Working in awkward or cramped positions* & $51.9 \%$ & $35.2 \%$ & $11.1 \%$ & $1.9 \%$ \\
\hline Working in the same position for long periods* & $52.7 \%$ & $34.6 \%$ & $10.9 \%$ & $1.8 \%$ \\
\hline Bending or twisting your back in an awkward way* & $50.0 \%$ & $18.5 \%$ & $24.1 \%$ & $7.4 \%$ \\
\hline Reaching or working away from your body & $44.4 \%$ & $25.9 \%$ & $25.9 \%$ & $3.7 \%$ \\
\hline Unanticipated sudden movement or falls of patient* & $46.3 \%$ & $14.8 \%$ & $25.9 \%$ & $12.9 \%$ \\
\hline Assisting patient during gait activities & $15.4 \%$ & $23.1 \%$ & $36.5 \%$ & $25.0 \%$ \\
\hline Lifting or transferring dependant patients* & $46.3 \%$ & $37.0 \%$ & $14.8 \%$ & $1.9 \%$ \\
\hline Working with confused or agitated patients & $17.3 \%$ & $26.9 \%$ & $36.5 \%$ & $19.2 \%$ \\
\hline Carrying, lifting or moving heavy materials/equipment & $15.1 \%$ & $35.9 \%$ & $30.2 \%$ & $18.9 \%$ \\
\hline Working at or near your physical limits & $27.3 \%$ & $32.7 \%$ & $27.3 \%$ & $12.7 \%$ \\
\hline Continuing to work when injured or hurt & $34.6 \%$ & $40.0 \%$ & $18.2 \%$ & $7.3 \%$ \\
\hline Work scheduling (overtime, irregular shifts, length) & $17.6 \%$ & $31.4 \%$ & $31.4 \%$ & $19.6 \%$ \\
\hline Inadequate training in injury prevention* & $5.9 \%$ & $11.8 \%$ & $25.5 \%$ & $56.9 \%$ \\
\hline
\end{tabular}

Table 4: Physiotherapists' response to injury.

\begin{tabular}{|l|l|}
\hline RESPONSE TO INJURY & \\
\hline Sought physiotherapy treatment* & $71.4 \%$ \\
\hline Exercise or posture program* ${ }^{\star}$ & $71.4 \%$ \\
\hline Modified their physiotherapy techniques* & $50 \%$ \\
\hline Took medication* & $50 \%$ \\
\hline Consulted a doctor & $19.6 \%$ \\
\hline Had diagnostic imaging (X-rays, MRI, CT etc.) & $16.1 \%$ \\
\hline Changed their work settings & $12.5 \%$ \\
\hline Nothing & $8.9 \%$ \\
\hline Officially reported the injury & $8.9 \%$ \\
\hline Changed type of patient predominantly treating & $7.1 \%$ \\
\hline Sought alternative treatments & $7.1 \%$ \\
\hline Time off on sick leave & $7.1 \%$ \\
\hline Used braces, splints or other orthosis & $7.1 \%$ \\
\hline Decreased patient contact hours & $5.4 \%$ \\
\hline Plan to retire early & $5.4 \%$ \\
\hline Changed your work duties & $3.7 \%$ \\
\hline Lodged a claim to workers compensation or PPS & $1.8 \%$ \\
\hline Taken time off on workers compensation or PPS & $1.8 \%$ \\
\hline Other consequences & $0.0 \%$ \\
\hline Undergone surgery & $0.0 \%$ \\
\hline
\end{tabular}

pists might give a more correct representation of work related low back pain in the profession because $5.4 \%$ of respondents indicated that they plan to retire early due to pain or injury.

The self protective behaviour most commonly used by respondents to reduce strain on their body when working is getting someone to help them handle a heavy patient $(40 \%)$, modify their position or the position of the patient (58.2\%), or adjust the height of the plinth or bed $(50 \%)$. A large number of respondents indicated that they never stop a treatment if it causes or aggravates their discomfort (46.3\%).

Although $92.7 \%$ of the respondents received training in kinetic handling, the high incidence of WRLBP suggests that it is rather the nature of the job design which predisposes physiotherapists to injury and not a lack of education. Only $6 \%$ of respondents stated that inadequate training had an influence on their work related low back discomfort or injury. This is consistent with Gardner et al. (2001) who also had a $6 \%$ result. A fair comment was made by one of the respondents that "physiotherapists do 
not always practice what they preach" about back care and therefore there may be a discrepancy between knowledge and the actual application of the knowledge. Further investigation regarding therapists' own application of back care could be done.

\section{CONCLUSION}

The results obtained in the study showed that WRLBP is a prevalent problem within the physiotherapy profession in Bloemfontein. The unacceptable irony is that physiotherapists are primarily involved in the treatment of back pain and yet they themselves suffer from this affliction, despite knowledge and extensive training in kinetic handling principles. It is however apparent that the inherent nature of physiotherapy practice predisposes therapists to WRLBP. Further research could be conducted to determine how effectively physiotherapists apply kinetic handling principles in practice and to determine the incidence of pain and injury to other areas of the body for example neck, thoracic area, wrist, fingers and thumbs. Deyo, Loeser, and Bigos (1990) determined that $80 \%$ of the general population experience back pack at some stage. It would be interesting to compare low back pain among physiotherapists and members of the general population in the same age bracket to conclusively determine whether it is the design of the job that predisposes physiotherapists to low back pain.

Research to determine the incidence of pain and injury to other areas of the body for example neck, thoracic area, wrist, fingers and thumbs could also be conducted in South Africa and a study including retired physiotherapists might give a more correct representation of work related low back pain in the profession.

\section{ACKNOWLEDGEMENTS}

The researchers would like to thank the participants.

\section{REFERENCES}

Best, M., Cromie, J. and Robertson V. 2000. Work related musculoskeletal disorders in physical therapists: Prevalence, severity, risks and responses. Physical Therapy. 80(4): 336-351.

Best, M., Cromie, J. and Robertson, V. 2001. Occupational health and safety in physiotherapy: Guidelines for practice. Australian Journal of Physiotherapy. 47:43-50.

Bork, B. et al. 1996. Work related musculoskeletal disorders among physiotherapists. Physical Therapy. 76(8): 827-835.

Cromie. JE, Roberstson VJ, Best MO. 2000. Work-related musculoskeletal disorders in physical therapists: prevalence, severity, risks and responses. Physical Therapy. 80: 336-351.

Deyo, R.A.; Loeser, J.D.; Bigos, S.J. 1990. Herniated Lumbar Intervertebral Disc. Annals of Internal Medicine. 112(8): 589-603.

Gardner, D. and West, D. 2001. Occupational injuries of physiotherapists in North and Central Queensland. Australian Journal of Physiotherapy. 47: 179-187.
Glover, W. 2002. Work-related strain injuries in physiotherapists: prevalence and prevention of musculoskeletal disorders. Physiotherapy. 88(6): $364-372$.

Holder, N. et al. 1999. Cause, prevalence and response to occupational musculoskeletal injuries reported by physical therapists and physical therapist assistants. Physical Therapy. 79(7): 643-651.

Igumbor, E., Madzire, D. and Useh, U. 2003. An epidemiological study of work related low back pain among physiotherapists in Zimbabwe. SA Journal of Physiotherapy. 59(3): 7-14.

Miezejewski M, Kumar S. 1997. Prevalence of low back pain among physical therapists in Edmonton, Canada. Disability Rehabilitation 19: 309-317.

Molumphy M, Unger B, Jensen GM, Lopopolo RB. 1995. Incidence of work-related low back pain in physiotherapists. Physical Therapy 65:482-486.

Scholey M, Hair M. 1989. Back pain in physiotherapists involved in back care education. Ergonomics 32:179-190.

Stubbs DA, Buckle PW, Hudson MP, Rivers PM, Worringham CJ. 1983. Back pain in the nursing profession: epidemiology and pilot methodology. Ergonomics 26:755-765.

\section{To advertise in the South African Journal of Physiotherapy contact Americo at SASP Head Office: Tel: (011) 485-1467, Fax: (011) 485-1613 E-mail: pr@saphysio.co.za}

